\title{
United States Food and Drug Administration seeks global regulatory regime
}

$\mathrm{T}$ he United States Food and Drug Administration (FDA) is proposing to develop and lead a more coordinated global approach to the inspection and monitoring of foods, drugs and medical devices.

Globalization is forcing the development of a more coordinated international approach to regulation of such products, much as it affected the rapid spread of infectious diseases and the need for global responses in the area of public health, the FDA argues in a recent report, Pathway to Global Product Safety and Quality (www.fda .gov/downloads/AboutFDA/Centers Offices/OC/GlobalProductPathway /UCM259845.pdf).

"Globalization has fundamentally altered the economic and security landscape and demands a major change in the way FDA fulfills its mission to promote and protect the health of American people," the report states, while arguing that a more global response is needed to such global trends as the rise of emerging markets, the scarcity of natural resources and an increased flow of goods across multiple borders, which makes it difficult to identify the source of an imported product.

"Global production of FDA-regulated goods has exploded over the past ten years. In addition to an increase in imported finished products, manufacturers increasingly use imported materials and ingredients in their U.S. production facilities, making the distinction between domestic and imported products obsolete," states Dr. Margaret Hamburg, commissioner of food and drugs, in a press release (www.fda.gov /newsevents/newsroom/pressannounce ments/ucm259848.htm).

"There has been a perfect storm more products, more manufacturers, more countries and more access. A dramatic change in strategy must be implemented."

The FDA said it will have to make

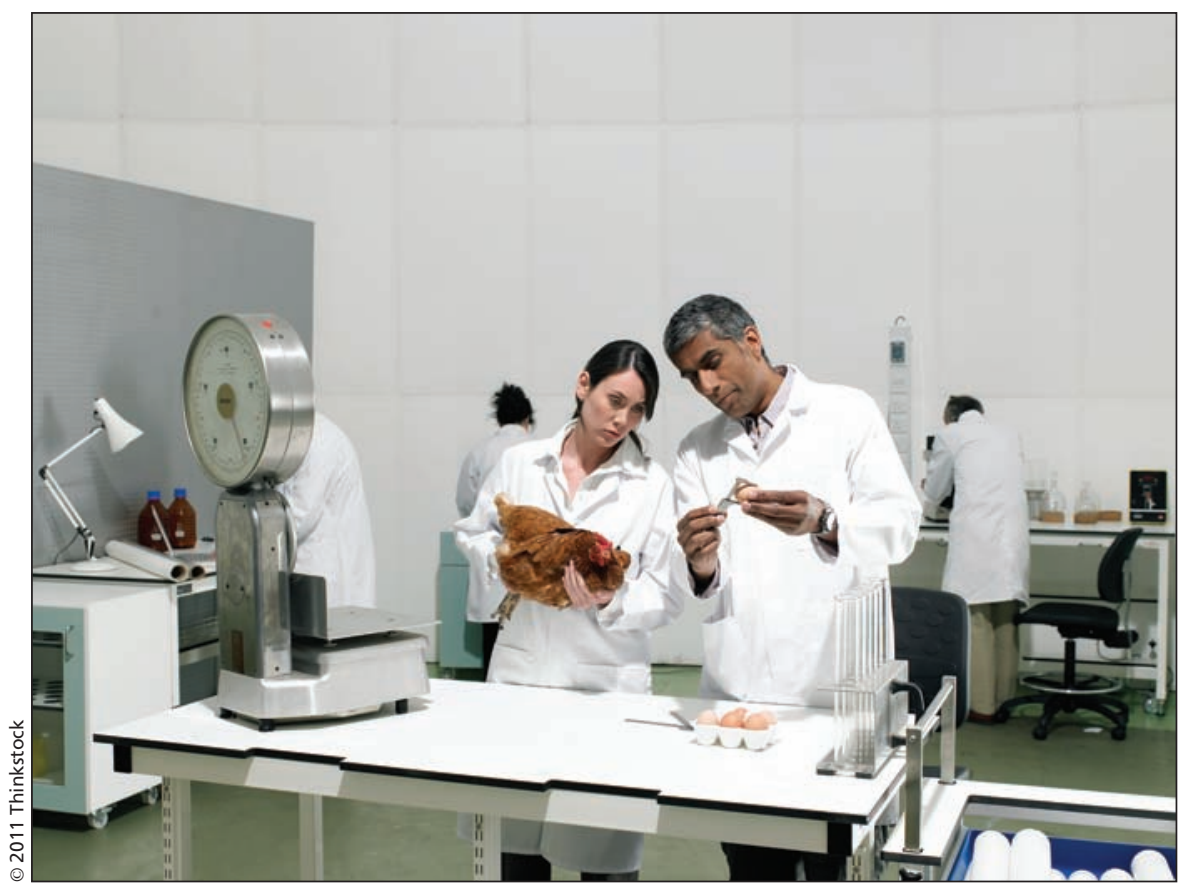

Among changes being advocated by the United States Food and Drug Administration are more inspections undertaken by private third parties.

four major changes in the way it regulates products, to wit:

- The development of a global coalition of regulators, "beginning with a core group of partners," to establish a structure for more systematic information-sharing and membership standards. Initially, the FDA will seek partnerships with countries having comparable standards.

- The development of a global data system to allow information to be reported and shared in standardized fashion, while protecting against potential threats, such as food adulteration. To that end, the FDA indicated it will look for help from groups like Interpol, who have built complex and effective informationsharing systems across participating countries.

- Bolstering of data collection capability, including more training and hiring of staff with risk analysis expertise.
- Allocating available resources "based on risk" and undertaking inspections through greater use of public and private third parties. The breadth of an inspection will be "based on the degree of risk associated with the particular facility," the report says. That will enable countries to conduct multiple inspections of low-risk sites in a short period of time. The FDA also intends to establish an audit infrastructure to verify third-party information.

The FDA indicated that it has little option but to rely more heavily on the efforts of international regulator partners because the increasing complexity of manufacturing processes make them less transparent and harder to detect whether foreign products are fraudulent, adulterated or tampered with by terrorists.

But many of the critical details surrounding the new FDA regime have yet to be ironed out. For example, exactly 
how much authority the FDA will delegate to third parties, and what security checks will be put in place therein, "will need to be determined in the future," FDA spokesperson Douglas Karas writes in an email.

The FDA also stressed that it expects it will take years to fully develop and implement a global regulatory approach.

Canada appears eager to clamber aboard. "Within the increasingly complex regulatory environment, Health Canada's Health Products and Food
Branch (HPFB) embraces international regulatory cooperation with other country regulators, in addition to international and multilateral organizations as a means to strengthen its capacity to make regulatory decisions based on the best available science," spokeswoman Olivia Caron writes in an email.

While Canada's Food and Drug Regulations are not identical to those of the FDA, harmonization of standards would be important, she added.

The Canadian Food Inspection Agency believes a global coalition would help ensure that food imports meet Canadian safety requirements, Alice d'Anjou, senior media relations officer writes in an email. "This collaborative approach helps to reduce duplication of efforts, maximize resources, facilitate identification of and faster responses to import threats, and provides a broader picture of food safety systems in an increasingly global world." — Erin Walkinshaw, Ottawa, Ont.

CMAJ 2011. DOI:10.1503/cmaj.109-3954 